\title{
Effect of Oncoxin, a Food Supplement, on Terminal-stage Hepatocellular Carcinoma Patients
}

\author{
Mamun Al Mahtab ${ }^{1}$, Faysal Ahmed ${ }^{2}$, Dulal Chandra Das ${ }^{3}$, Sheikh Mohammad Noor-E-Alam ${ }^{4}$, Ayub A Mamun $^{5}$
}

\begin{abstract}
Background: Liver cancer is currently the second-most common cause of cancer-related deaths worldwide and hepatocellular carcinoma (HCC) accounts for more than $90 \%$ of liver cancers. Patients with terminal HCC are those presenting with very poor Eastern Cooperative Oncology Group (ECOG) Performance Status 3-4 with tumors beyond the transplantation threshold. Their management of terminal HCC is only palliative support. Oncoxin is a nutritional supplement that is used as an over-the-counter nutritional prophylaxis for cancers. Our aim was to evaluate the effect of Oncoxin in terminal HCC patients along with the best supportive care (BSC), comparing that to the terminal-stage HCC patient only treated with BSC to determine the survival outcome as well as performance status, assessed by the ECOG Performance Status Scale.

Materials and methods: This was a randomized control trial conducted at the Hepatology Department, Bangabandhu Sheikh Mujib Medical University (BSMMU) from December 2019 to February 2021. A total of 60 patients were included (30 patients for Oncoxin with BSC and 30 patients for BSC only) and randomized into two groups. They were followed up for 3 months.

Results: In this study, it was observed that at 60 days, eight (26.7\%) patients survived in the Oncoxin group and one (3.3\%) patient survived in the BSC group. The difference was statistically significant $(p<0.05)$. However, the Oncoxin administration had no survival benefit at 30 and 90 days follow up. After 30 days of treatment, a comparison of ECOG Performance Status between groups showed that all 12 (100\%) patients in the Oncoxin group were in grade 3, while in the BSC group, four (44.4\%) patients were in grade 3 and five (55.6\%) patients were in grade 4. These differences were statistically significant.

Conclusion:The study shows that Oncoxin appears to increase the survival of some, but not all, patients with terminal-stage HCC. The improvement of ECOG Performance Status was also observed.

Keywords: Food supplement, Hepatocellular carcinoma, Oncoxin, Terminal stage.

Bengal Physician Journal (2021): 10.5005/jp-journals-10070-7061
\end{abstract}

\section{INTRODUCTION}

Hepatocellular carcinoma (HCC) is the sixth most common cancer in the world and the second most common cause of cancer deaths globally. ${ }^{1}$ It is the fifth most common cancer in men and the eighth most common in women. ${ }^{2}$ The incidence of HCC in Bangladesh is the 8th among all cancers. HCC ranks the third among all cancerrelated deaths in Bangladesh. ${ }^{3-5}$ However, in Bangladesh, most patients are diagnosed with advanced HCC due to the lack of the effective surveillance and monitoring system for HCC. The aim of the study is to observe the surviving time and improvement of the quality of life with oncoxin, a nutritional supplement.

Oncoxin is used as nutritional prophylaxis for cancers. It acts by the antioxidant effect and activating the immune system. Oncoxin inhibits the proliferation of HCC cell lines in a time and dose-dependent manner. The effect of Oncoxin is due to the induction of cell cycle arrest in all phases in HCC cell lines. Oncoxin has anticancer and anti-inflammatory actions. It stimulates cancer cell apoptosis, thus inhibiting cancer cell proliferation and differentiation, angiogenesis, invasion, and metastasis. It also stimulates anti-inflammatory cytokines and other cytokines and at the same time inhibiting pro-inflammatory cytokines (Table 1).

Best supportive care is defined as the best supportive treatment measures for cancer patients. The European Organization for Research and Treatment of Cancer (EORTC) defines BSC as, "supportive treatment interventions for cancer patients encompass the multiprofessional approach to the individual all-encompassing physical, psychosocial, spiritual, and cultural needs and should be available at all times of the illness for patients of all ages and
${ }^{1-5}$ Department of Hepatology, Bangabandhu Sheikh Mujib Medical University, Dhaka, Bangladesh

Corresponding Author: Mamun Al Mahtab, Department of Hepatology, Bangabandhu Sheikh Mujib Medical University, Dhaka, Bangladesh, Phone: +880 1711567275, e-mail: shwapnil@agni.com

How to cite this article: Mahtab MAl, Ahmed F, Das DC, et al. Effect of Oncoxin, a Food Supplement, on Terminal-stage Hepatocellular Carcinoma Patients. Bengal Physician Journal 2021;8(3):63-66.

Source of support: Nil

Conflict of interest: None

Table 1: Composition of oncoxin

\begin{tabular}{ll}
\hline L-Arginine & $72 \mathrm{mg}$ \\
N-Acetyl cysteine & $25.5 \mathrm{mg}$ \\
Vitamin C & $20 \mathrm{mg}$ \\
Zinc sulfate & $12 \mathrm{mg}$ \\
Green tea extract & $7.5 \mathrm{mg}$ \\
Manganese sulfate & $3 \mathrm{mg}$ \\
Cinnamone & $0.9 \mathrm{mg}$ \\
Vitamin B6 & $650 \mathrm{microg}$ \\
Organic germanium & $35.7 \mathrm{mg}$ \\
Guar gum & $122.7 \mathrm{mg}$ \\
\hline
\end{tabular}

(-) The Author(s). 2021 Open Access This article is distributed under the terms of the Creative Commons Attribution 4.0 International License (https://creativecommons. org/licenses/by-nc/4.0/), which permits unrestricted use, distribution, and non-commercial reproduction in any medium, provided you give appropriate credit to the original author(s) and the source, provide a link to the Creative Commons license, and indicate if changes were made. The Creative Commons Public Domain Dedication waiver (http://creativecommons.org/publicdomain/zero/1.0/) applies to the data made available in this article, unless otherwise stated. 
regardless of the current treatment intention of the interventions directed against the illness." This is an approach that improves the quality of life of patients through the management of pain as well as other physical, psychosocial, and spiritual problems.

\section{Materials and Methods}

This was a randomized control trial conducted at the Department of Hepatology, BSMMU, Dhaka, from December 2019 to February 2021. The research protocol was approved by the Institutional Review Board of BSMMU. Sixty patients of HCC were included. Patients with ECOG Performance Status $>2$, age $>18$ years, and of both sexes were included. Patients diagnosed with another cancer in addition to $\mathrm{HCC}$, with comorbid conditions like severe CCF, IHD, recent MI, COPD, CKD, etc., and patients of HCC with ECOG Performance Status $<2$ were excluded from the study. A written informed consent for inclusion in the trial was obtained from the patients, who were randomized into two different groups. One group was selected for the Oncoxin therapy with BSC (Oncoxin group) and another was selected for only BSC (BSC group). Oncoxin group patients received Cap. Oncoxin $(300 \mathrm{mg})$ thrice daily by mouth in addition to BSC. BSC group patients received only the BSC.

All patients were followed up for at least 3 months or up to death. Adverse events were closely monitored. The death of admitted patients was recorded physically and those who died outside were recorded over the telephone.

Serum alanine aminotransferase (ALT), aspartate aminotransferase (AST), total bilirubin, prothrombin time (INR), serum albumin, serum creatinine, serum electrolyte, complete blood count (CBC), alpha-fetoprotein (AFP), hepatitis B surface antigen (HBsAg), and if positive, hepatitis $B$ e antigen ( $\mathrm{HBeAg})$, anti $\mathrm{HBe}$ was done and if negative, anti-HBc ( total) was done. HBV DNA estimation was done with the real-time PCR method and Anti HCV was done and if positive, HCV RNA estimation was done. Abdominal ultrasound and CT scan/MRI and upper GI endoscopy were done. Fine needle aspiration for cytology was done where CT scan/MRI finding was inconclusive.

The statistical analysis was done using the statistical package for Social Sciences version 21.0 for windows (IBM Corp: Armonk, NY, USA). $p$ values $<0.05$ were considered significant.
The overall fitness of a patient was often assessed by the ECOG performance status scale. The outcome for patients with a performance status of 3 or 4 is worse in almost all malignancies.

\section{Results}

Socio-demographic profile and baseline clinical presentations of study participants $(n=60)$ are shown in Table 2 . The mean age was $49.67 \pm 11.046$ years in the Oncoxin group and $46.87 \pm 10.030$ years in the BSC group. There was male predominance in both groups and in both groups, abdominal pain was the most common presentation. Table 3 shows the baseline biochemical profiles of study participants.

It was observed that $24(80 \%)$ patients had hepatitis B in the Oncoxin group and $26(87 \%)$ in the BSC group as the cause of HCC. Hepatitis $C$ was found in two (7\%) patients in the Oncoxin group and two (7\%) patients in the BSC group. Both hepatitis B and hepatitis $C$ were found in two (7\%) patients only in the Oncoxin group (Fig. 1).

A baseline comparison between ECOG Performance Status in both study groups did not show a statistically significant difference $(p>0.05)$. When compared between both groups after 30 days, ECOG Performance Status was grade 3 in 12 (100\%) patients in the Oncoxin group, but in the BSC group, ECOG Performance Status was grade 3 in only four (44.4\%) patients and grade 4 in rest five $(55.6 \%)$ patients. These differences were statistically significant $(p<0.05)$ (Table 4). However, a comparison of ECOG Performance Status between both groups after 60 days was not statistically significant.

After 30 days of initiation of treatment, the follow up did not show a statistically significant survival benefit in the Oncoxin group. However, after 60 days of initiation of treatment, follow up showed eight (26.7\%) patients survived in the Oncoxin group, while one (3.3\%) patient survived in the BSC group. This difference was statistically significant 0.03 ( $p<0.05$ ) (Table 4$)$.

The median survival for all the patients, Oncoxin group, and BSC group was 24, 23, and 24 days, respectively. The Kaplan-Meier curve for the overall survival showed a significant survival difference of 0.03 ( $p<0.05$ ) between the two groups at 60 days (Fig. 2), but at 30 and 90 days, it revealed no statistically significant difference $(p>0.05)$.

Table 2: Sociodemographic profile and baseline clinical presentation of study participants

\begin{tabular}{lcccc}
\hline Characteristics & $\begin{array}{c}\text { Oncoxin } \\
(n=30)\end{array}$ & $\begin{array}{c}\text { BSC } \\
(n=30)\end{array}$ & $\begin{array}{c}\text { Total } \\
(n=60)\end{array}$ & $p$ value \\
\hline Age (years) & $49.67 \pm 11.05$ & $46.87 \pm 10.03$ & $48.27 \pm 10.56$ & ${ }^{a} 0.31^{\text {ns }}$ \\
Sex & & & & \\
Male & $29(97 \%)$ & $26(87 \%)$ & $55(92 \%)$ & ${ }^{b} 0.31^{\text {ns }}$ \\
Female & $1(3 \%)$ & $4(13 \%)$ & $5(8 \%)$ & \\
Presentation & & & & \\
Abdominal pain & $27(90 \%)$ & $27(90 \%)$ & $54(90 \%)$ & ${ }^{b} 0.15^{\text {ns }}$ \\
Jaundice & $24(80 \%)$ & $24(80 \%)$ & $48(80 \%)$ & ${ }^{b} 0.29^{\text {ns }}$ \\
Ascites & $27(90 \%)$ & $21(70 \%)$ & $48(80 \%)$ & ${ }^{b} 0.06^{\text {ns }}$ \\
Encephalopathy & $14(46.7 \%)$ & $13(43.3 \%)$ & $27(45 \%)$ & ${ }^{b} 0.79^{\text {ns }}$ \\
\hline
\end{tabular}

ns, not significant

Values are expressed as Mean \pm SD and within parenthesis percentage (\%)

${ }^{a} p$ value reached from unpaired $t$-test

${ }^{b} p$ value reached from Chi-Square $\left(\chi^{2}\right)$ test 
Table 3: Baseline biochemical profile of study participants

\begin{tabular}{|c|c|c|c|c|}
\hline Parameter & $\begin{array}{l}\text { Oncoxin } \\
(n=30)\end{array}$ & $\begin{array}{c}B S C \\
(n=30)\end{array}$ & $\begin{array}{c}\text { Total } \\
(n=60)\end{array}$ & $p$ value \\
\hline $\begin{array}{l}\mathrm{Hb}(\mathrm{g} / \mathrm{dL}) \\
(\text { mean } \pm \mathrm{SD})\end{array}$ & $11.03 \pm 1.87$ & $10.79 \pm 2.50$ & $10.91 \pm 2.19$ & ${ }^{a} 0.68^{\text {ns }}$ \\
\hline $\begin{array}{l}\text { Platelet }\left(\times 10^{3} / \mathrm{mm}^{3}\right) \\
(\text { mean } \pm \mathrm{SD})\end{array}$ & $191 \pm 127$ & $233 \pm 116$ & $212.18 \pm 122$ & ${ }^{a} 0.19^{\text {ns }}$ \\
\hline $\begin{array}{l}\operatorname{ALT}(\mathrm{U} / \mathrm{L}) \\
(\operatorname{mean} \pm \mathrm{SD})\end{array}$ & $74.17 \pm 40.16$ & $277.07 \pm 811.04$ & $175.62 \pm 578.5$ & ${ }^{c} 0.28^{\text {ns }}$ \\
\hline $\begin{array}{l}\text { S. bilirubin } \\
\text { (mean } \pm \text { SD) }\end{array}$ & $5.79 \pm 5.96$ & $8.28 \pm 6.13$ & $7.04 \pm 6.13$ & ${ }^{c} 0.07^{\text {ns }}$ \\
\hline $\begin{array}{l}\text { S. albumin } \\
\text { (mean } \pm \text { SD) }\end{array}$ & $2.44 \pm 0.40$ & $2.69 \pm 1.08$ & $2.56 \pm 0.82$ & ${ }^{a} 0.23^{\mathrm{ns}}$ \\
\hline $\begin{array}{l}\text { INR } \\
(\text { mean } \pm S D)\end{array}$ & $1.69 \pm 0.40$ & $1.59 \pm 0.57$ & $1.64 \pm 0.50$ & ${ }^{a} 0.43^{\text {ns }}$ \\
\hline CPT score (mean \pm SD) & $11.00 \pm 1.02$ & $10.77 \pm 1.07$ & $10.50 \pm 2.02$ & ${ }^{a} 0.31^{\mathrm{ns}}$ \\
\hline \multicolumn{5}{|l|}{$\operatorname{AFP}(n g / m L)$} \\
\hline$<200$ & $8(27 \%)$ & $11(37 \%)$ & $19(32 \%)$ & ${ }^{b} 0.58^{\mathrm{ns}}$ \\
\hline$\geq 200$ & $22(73 \%)$ & $19(63 \%)$ & $41(68 \%)$ & \\
\hline
\end{tabular}

ns, not significant

${ }^{a} p$ value reached from unpaired $t$-test

${ }^{b} p$ value reached from Chi-Square $\left(\chi^{2}\right)$ test

${ }^{c} p$ value reached from Independent samples Mann-Whitney $\mathrm{U}$ test

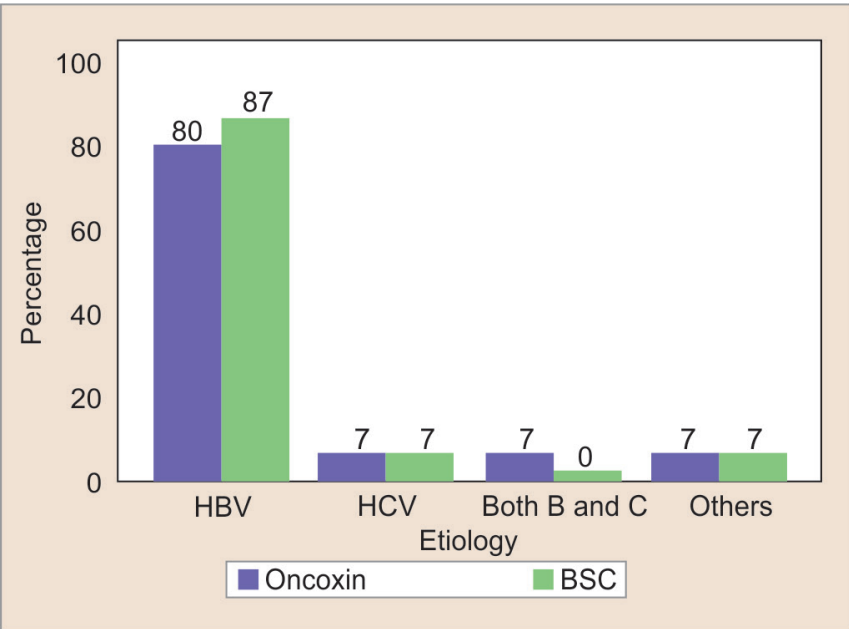

Fig. 1: Etiological distribution of study populations

Table 4: Outcome of the patients after 60 days of follow-up

\begin{tabular}{lccccc}
\hline & \multicolumn{2}{c}{$\begin{array}{c}\text { Oncoxin Group } \\
(n=30)\end{array}$} & \multicolumn{2}{c}{$\begin{array}{c}\text { BSC Group } \\
(n=30)\end{array}$} & \\
\cline { 2 - 5 } Outcome & $N$ & $\%$ & $N$ & $\%$ & p value \\
\hline Survived & 8 & 26.7 & 1 & 3.3 & $0.03^{\mathrm{s}}$ \\
Dead & 22 & 73.3 & 29 & 96.7 & \\
\hline
\end{tabular}

s, significant

$p$ value reached from Fisher's Exact test

\section{Discussion}

In the present study, it was observed that 60 days of survival in the Oncoxin group were statistically significant. It is almost similar to the observation by Mahtab et al. ${ }^{6}$ The median survival time of the participants of this study was low. The study population came to the hospital for treatment with terminal-stage HCC, which may be the cause of the shorter median survival observed in our study. This is

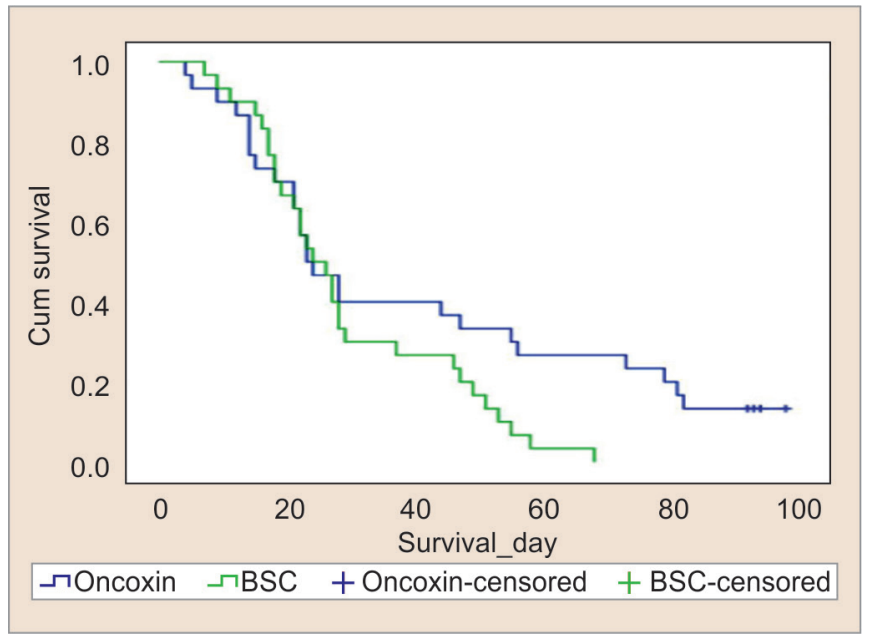

Fig. 2: Kaplan-Meier curve for survival

a limitation of this study. However, Kato et al. ${ }^{7}$ also observed a lower median survival time of 1 month in terminal-stage HCC patients.

The present study did not observe any adverse effects of Oncoxin. Mahtab et al. ${ }^{6}$ also reported a similar observation.

The study has shown that Oncoxin appears to increase the survival of some, but not all patients with terminal HCC. Most of the patients receiving only BSC died within 60 days after their entry in this study. Patients receiving Oncoxin on the other hand showed better survival as 8 of $30(26.7 \%)$ patients with terminal HCC survived for more than 60 days and 4 of 30 (13.3\%) patients survived for more than 90 days after receiving Oncoxin.

\section{Conclusion}

Oncoxin is a food supplement that showed better survival in terminal HCC. More importantly, it was observed that Oncoxin significantly improves the quality of life in terminal-stage 
HCC patients by improving ECOG Performance Status. So, we can conclude that Oncoxin may be considered as a palliative care medicine in terminal-stage HCC patients. However, this observation needs validation with the further multicenter study.

\section{References}

1. Ferlay J, Soerjomataram I, Dikshit R, et al. Cancer incidence and mortality worldwide: Sources, methods and major patterns in GLOBOCAN 2012. Int J Cancer 2015; 136(5):p. 359-386. DOI: 10.1002/ ijc.29210.

2. Forman D, Bray F, Brewster DH, et al. Cancer Incidence in Five Continents Vol. X. IARC Scientific Publications No. 164. International Agency for Research on Cancer Lyon, France 2014.

3. Jabeen S, Islam MJ, Talukder MH, et al. Pathoepidemiology of Cervical Cancer in National Institute of Cancer Research and Hospital of
Bangladesh. Journal of Dhaka Medical College 2015;23(2):p.203-210. DOI: 10.3329/jdmc.v23i2.25392.

4. Mahtab MA, Karim F, Foster G, et al. Prevalence and risk factors of asymptomatic hepatitis $C$ virus infection in bangladesh. J Clin Exp Hepatol 2011;1(1):p.13-16. DOI: 10.1016/S0973-6883(11)60111-4. PMID: 25755305; PMCID: PMC3940088.

5. Hussain SA, Sullivan R. Cancer control in Bangladesh. Jpn J Clin Oncol 2013;43(12):p.1159-1169. DOI: 10.1093/jjco/hyt140. PMID: 24163419; PMCID: PMC3842101.

6. Al-Mahtab M, Akbar SM, Khan MS, et al. Increased survival of patients with end-stage hepatocellular carcinoma due to intake of ONCOXIN ${ }^{\oplus}$, a dietary supplement. Indian J Cancer 2015;52(3):p.443-446. DOI: 10.4103/0019-509X.176699. PMID: 26905163.

7. Kato $\mathrm{H}$, Yoshida $\mathrm{H}$, Taniguch $\mathrm{H}$, et al. Cyberknife treatment for advanced or terminal stage hepatocellular carcinoma. World J Gastroenterol 2015;21(46):p.13101-13112. DOI: 10.3748/wjg.v21. i46.13101. PMID: 26673627; PMCID: PMC4674729. 